\title{
Assessing an innovative teaching model for effective and engaging library instruction
}

$\mathbf{T}$

he flipped classroom is a teaching model that inverts the traditional lecture-plushomework formula. By moving the delivery of foundational principles to digital media, such as video lectures or tutorials, class time is freed up for engaging activities that allow students to apply these basics to practical scenarios in the presence of their instructor.

The flipped classroom is attributed to high school teachers Jonathan Bergmann and Aaron Sams, but many creative teachers have used variations of this method for years. ${ }^{1}$ Librarians are also taking part in this trend, as evidenced by another CERL News article from earlier this year, "Four quick flips: Activities for information literacy classroom." Information literacy (IL) instruction can especially benefit from a model that makes the best use of class time by inviting students to dive right in and encounter the real-world complications of library research.

\section{The setting}

At Towson University's Albert S. Cook Library, research and instruction librarians teach course-integrated IL sessions to students at all levels. These sessions can vary from a "one-shot" general orientation on library collections and resources to a series of sessions scheduled throughout a semester to support scaffolded research assignments, depending on the needs of each course and the relationships between faculty and librarians.

Cook librarians are an independent and experimental bunch, regularly sharing teaching strategies and incorporating new technologies or techniques into their practice. This provided an ideal environment for investigating the use of the flipped classroom for IL instruction. In spring 2013, Cook librarians participated in a project to determine whether the flipped classroom model of teaching could be used to deliver engaging and effective library instruction.

\section{The project}

The components of the Cook flipped classroom project are:

- the pre-library session assignment;

- the in-class activities;

- the student, librarian, and faculty questionnaires used to gather data about the experience; and

- the librarian group interview used to gather more detailed feedback.

The project was implemented in 14 IL sessions by seven librarians. Ten of the sessions were freshman level courses, and four were upper-level courses. The sessions were taught in diverse subject areas, including education, political science, sociology, computer science, and English.

\section{Pre-library session assignments}

Cook Library's Help Guides, brief video tutorials created over several years, were used to build the pre-library session assignment.

Sara Arnold-Garza is residency librarian at Towson University's Albert S.Cook Library, e-mail:sarnoldgarza@ towson.edu

C 2014 Sara Arnold-Garza 
These guides address topics like the differences between scholarly and popular materials, building a database search, and using the library website, among others. Generally a combination of videos was assigned, not exceeding 20 minutes total. Each assignment included a quiz or other task, which implied to the student that the activity was a requirement, provided an opportunity for students to reflect on their own understanding of the material, and gave librarians an idea of the number of students who completed the assignment.

\section{In-class activities}

In class, librarians guided students through active learning exercises that required them to apply the concepts introduced by the prelibrary session assignment. These activities varied by class and librarian. In some cases, class time was used for a brief review of concepts introduced by the pre-library session assignment, followed by unstructured work time for exploring databases or library collections to find sources for a course assignment.

Sessions with upper-level students began with an electronic poll for material review and reflection, followed by guided discussions on arrangement of relevant collections and other pertinent topics, chunked activities for students to complete in groups, and worksheets used to guide student progress. Many flipped sessions fell somewhere between these two models, with some level of introductory review, structured activity during class, guided discussions, and worksheets.

\section{Data collection}

In order to assess these efforts, we collected data using two types of instruments: questionnaires and a group interview. ${ }^{3}$

Questionnaires were collected from students, faculty, and librarians following the flipped sessions. Each group was asked to agree or disagree with statements about their experience and observations, and provided a chance to offer free-text feedback in a final question.

A group interview was conducted with librarians who taught Cook flipped classroom sessions to gather more detailed feedback about their observations. The questions were determined by the highlights and themes that emerged from the questionnaire responses.

\section{The feedback}

\section{Student questionnaire}

Student response to the flipped classroom was positive, with most students generally agreeing that they felt the model was helpful and supported their learning. In fact, more than $90 \%$ of 148 participating students agreed that:

- they had completed the pre-library session assignment,

- the pre-library session assignment provided information that was helpful for completing research assignments, and

- the in-class activities supported understanding of the concepts presented in the pre-library session assignment.

Additionally, 86\% agreed that they learned from in-class activities.

The trend was not complete, however. Forty-five percent indicated they would still rather have class time devoted to explanation of key concepts, rather than getting a pre-library session assignment and using class time for activities. It is not clear why nearly half of the respondents would prefer a traditional lecture model, despite their agreement that the flipped session supported their learning. Perhaps the requirement for work outside of class, and the increased responsibility for their own learning make this model less appealing to students.

Student comments were not abundant: only 14\% (21 of 148 respondents) left comments. Many comments did not provide additional insight, instead giving generally positive feedback such as "very helpful" or "It was a good experience over all." However several comments did provide specific feedback about the student experience. Multiple comments indicated that students feel the library sessions generally provide the same information or are repetitive from one class to another. Although not unique to the 
flipped classroom, this is useful feedback for improving our instruction program overall.

Other comments pointed out specific technology issues students encountered ("audio was touchy"), mentioned an aspect of the flipped classroom they appreciated ("homework load is lighter than usual," "It allows us students to ask questions and receive assistance immediately"), or offered suggestion for an improved experience ("wasn't necessary to spend so much time," "not enough time given to complete the in-class activities").

\section{Librarian questionnaire}

Overall, librarian response to the questionnaire was positive, but comments indicate some skepticism. Six of 7 librarians agreed that students came to class familiar with the pre-library session assignment concepts. Four of 6 librarians agreed that students engaged with each other in in-class discussion. All seven librarians agreed that students completed the in-class activities. Six of 7 librarians agreed that the flipped model allowed them to cover more concepts than in previous classes. Three of 5 librarians agreed that the model helped students reach a deeper understanding of concepts than in previous classes.

Only 2 of 7 librarians agreed that students asked for help during in-class activities. This result, along with some missing librarian responses to questions addressing student engagement and understanding described above, indicate that librarian conclusions are appropriately cautious. Several comments made in the final, open-text question clarify:

"I honestly was unable to get enough verbal feedback in the library session to be able to tell if some, all, or none of them understood the material from the library sessions...I couldn't really tell if they had a deeper understanding of one of the assignments."

"... they were a quiet bunch and did not ask me many questions while they worked on their in-class assignment... I didn't feel I was any more in-tune with their learning than I do during a typical library instruction class in which active learning exercises are incorporated, and that was disappointing to me."
"Cannot say that they had a 'deeper' understanding of concepts, but their answers to the quiz that I created indicated that they mostly 'got' the things that I thought were important. Whether they have retained any of this knowledge cannot be verified."

The librarians could not conclusively say whether students were engaged and what level of understanding they left with. The lack of an instrument that directly measured student learning limits the ability to draw conclusions. Other librarian comments provided more insight into classroom culture, time allotment, student interaction, and other themes, explored further in the group interview.

\section{Faculty questionnaire}

Faculty responses to this survey were very few $(n=4)$ and lacked detailed feedback. A summary is provided here for comprehensiveness' sake, but is not useful for making generalizations. Four of 4 faculty instructors agree on all of the following points:

- the pre-library session assignment addressed the research skills students need for their course work,

- the active learning component enhanced understanding of concepts introduced in the pre-library session assignment,

- students demonstrate understanding of the covered concepts in their classroom and coursework,

- students use the resources suggested by the library instruction, and

- the scheduling of the library session was timed appropriately.

Additionally, 4 of 4 faculty instructors disagree that the pre-library session assignment is too much for students to complete along with their usual course workload.

Two of 4 respondents provided comments in the open-ended text portion. These comments were positive, but brief:

"I loved that the flipped classroom model allowed for additional time during library sessions for students to actually work on their research. It was efficient and more productive this way." 
"I saw a remarkable difference with students having completed a section at home. They were more engaged, participated more, and were more successful during their classroom session."

\section{Librarian group interview}

A group interview yielded additional insight on the trends identified by the questionnaire: an overall positive response to the flipped classroom model, coupled with hesitance to make strong claims regarding the engagement and understanding outcomes for students. Interview questions focused on eliciting details about the librarians' observations of student behavior in class, their interaction with the librarian, use of class time, and the lessons or conclusions librarians brought away from the experience.

The comments made in the group interview indicate that the librarians found the experience beneficial to their teaching, and that they will use the flipped classroom in future semesters. A summary of the interview responses provides some insight into their thoughts:

- Re-thinking pedagogy. The deadlineoriented structure for planning flipped teaching, the reflective process built into gathering data from such a project, and the demand to think creatively about in-class activities reminded some of the value of such intentional pedagogy.

- Time juggling. There was a large amount of advanced scheduling for this project, including talking with faculty to get the assignment in the syllabus and creating and assigning the pre-class assignments. Additionally, changing the use of class time takes practice.

- Learner accountability. In-class group work can encourage students to prove their skills to their peers. Collaboration from students and "next-level" questions also help direct the course of class time to address their specific needs.

- Change is hard. Librarians struggled to "sell" the flipped classroom to faculty in some cases, and hope this experience will make that easier in the future. Librarians were also challenged to keep their own talking short. Some students displayed confusion about being asked to complete work in class or having their usual classroom model disrupted.

- Faculty/librarian relationships. Librarians talked with faculty about changing the way library instruction is integrated into courses. This might help faculty and librarians develop more sophisticated relationships that produce better IL outcomes for students.

\section{Conclusion}

The Cook flipped classroom project has made lasting changes to the way librarians will teach IL sessions at Towson University. Fears about students not completing pre-assigned work or not getting faculty agreement to try the flipped classroom were overcome by our experience. By planning ahead and collaborating with faculty to implement this model, librarians were able to flip some of their classes.

The question asked by this study, whether the flipped classroom model can be used to address engaging and effective library instruction, was not answered as clearly as hoped. Despite that, the outcomes were positive and have motivated Cook librarians to fine-tune their flipped classroom strategies to target innovative faculty, to further limit in-class lecture time, and to build well-structured in-class activities that specifically challenge students to use the foundational skills that pre-class assignments will teach.

\section{Notes}

1. J. Bergmann and A. Sams, Flip your classroom: Reach every student in every class every day (Eugene, Or.; Alexandria, Va.: International Society for Technology in Education; ASCD, 2012)

2. I. Datig and C. Ruswick, "Four quick flips: Activities for the information literacy classroom," College \& Research Libraries News, 74(5), 249-57.

3. These instruments can be found online at http://tinyurl.com/flippedquestionnaires and http://tinyurl.com/flippedinterview. $\boldsymbol{n}$ 